\title{
BIOPHILIC DESIGN CRITERIA FOR PRODUCTIVITY (BDCP) IN WORKSPACES
}

\author{
ASSOCIATE PROFESSOR: SAHAR MORSY MOHAMED MOHAMED ALY \\ HELWAN UNIVERSITY - FACULTY OF ENGINEERING - MATARYA- \\ ARCHITECTURAL ENGINEERING DEPARTMENT
}

\begin{abstract}
:
Urbanization had separated man from nature. Human beings spend a large amount of time indoors; whether they are at home or at work. The potential for sedentary indoor life increases. Workplace can be considered as stressful environment. Many stressors are there such as; timed tasks, KPIs, workloads, competition between colleagues all affect employees' welfare and hence, their productivity. Basophilic, the man-nature bond- offers a mean to help mitigate the employees' stress. It needs a plan to be applied in new and existing workplaces.

Many researchers have attempted in the past to complete a well rounded study of the theory of biophilia in the built environment. These studies lack an evidence based results and need connections with architecture design principles. This paper proposes a Biophilic Design Criteria for Productivity (BDCP) in workspaces through enhancing Occupants' connection with nature and thus offering productive environments.
\end{abstract}




\section{Keywords:}

Biophilia - Biophilic Design - productivity - workplaces 


\section{INTRODUCTION:}

The relationship between man and nature is eternal since the beginning of creation. We can argue that many of our current social, health and psychological problems are the result of separation from nature and living in a manufactured environment all the time. Being exposed to natural light and air - and in direct connection with natural element would no doubt have a great effect on improving the health and mood of a person.

Design of the modern urban built environment abuse the natural resources. Moreover, due to the poor built environment; many occupants' health issues have arisen. Biophilic Design offers a sustainable solution to mind both the environment and the mankind.

\section{WORKPLACES AS HIGH-STRESS ENVIRONMENTS:}

People spend 8 to 10 hours daily at work, or sometimes more than this. Workplaces could be described as high-stress environments that negatively affect users, where tasks are required at certain time, competency among colleagues, KPIs and many other management urges.

Professor Gary Cooper (cited by MI Business Magazine, 2015) ${ }^{\mathrm{i}}$ reports that up to one in five people have no natural elements within their workplace, and alarmingly nearly $50 \%$ of workers have no natural light at all. Pretty and Barton at the University of Essex found that "Five minutes of exposure to nature is enough to have a beneficial effect, but the more the better". Richard Louv agreed with all previous (scholars) and added that the more you connect your employees to their nature, the more productive they can be ${ }^{\mathrm{i}}$.

Productivity costs are difficult to quantify and assess as they are not clearly visible. Health should be the concern of the business as well as the employee; as absenteeism represents a high cost to any business. Sick leave can be considered to be a $100 \%$ loss of productivity and gains can be made if this is minimised. The mental health and well being of workers should also be considered to maintain a sustainable work force ${ }^{\text {ii }}$.

There are two main components of any workplace which come together to constitute an active workplace that fulfills all the user's needs and supports their activities. The 
first is physical; which is the environment itself with its tangible features. The environment includes the space, its dimensions, finishing materials, furniture, and colors, as well as the internal climate, including temperature, humidity and lighting. The second component is the culture; to name a few; the ideas, workflow, social interactions, behaviour and dress-code of workers in this environment.

In most cases, employees spend more than $50 \%$ of their waking hours at the workplace and that environment greatly influences their performance and mental framework. To create energised and productive workplaces, we need to design a workplace strategy that supports the two components of workplaces and enables efficient, happier and healthier employees to function.

The research is dedicated for the physical component since it is related to the biophilia. Notice that the components are coherent.

\section{RESEARCH PROBLEM:}

Nowadays; the architectural design process focuses on just fulfilling the functional space requirements of the buildings regardless the surrounding natural environment. The result has been an increasing disconnect between people and nature in the built environment reflected in inadequate contact with natural light, ventilation, materials, vegetation, views, natural shapes and forms, and in general beneficial contact with the natural world. ${ }^{\text {iii }}$

There are many articles that advocate the importance of applying the principles of biophilia in the workplace, but they all lack scientific research based on evidence. Moreover the architectural design parameters that help to apply biophilia in the builtenvironment are still vague.

This piece of work will draw connections between biophilia and workplace environment, highlight potentials of biophilia in improving workplaces, evolve the designers' understanding of biophilic design patterns to capture the positive physiological and psychological benefits offered by biophilia in the built-environment design process. 
Since productivity is the main concern in any workplace; the research at hand will address the main architectural design features in workplaces that enhance productivity based on Biophilic vision. This paper will propose a Biophilic Design Criteria for Productivity (BDCP) in the built environment through enhancing Occupants' connection with nature resulting in a productive workplace.

\section{RESEARCH STRUCTURE:}

To propose the BDCP for workplaces, a three phases study will be done:

First: a literature review to trace the models or patterns of biophilia in the builtenvironment and determine features of biophilic workplaces.

Second: some examples for biophilic workplaces will be analyzed to conclude biophilic features in them.

Third: A survey of the attitude of some employees towards biophilic features - that obtained from the previous two steps, on their satisfaction with their workplace and to rate the importance of these features.

\section{LITERATURE REVIEW; INTRODUCING BIOPHILIA INTO ARCHITECTURAL DESIGN:}

Biophilia, lexically, is "the innate affiliation people seek with other organisms and especially the natural world" according to the American biologist - Edward O'Wilson. He, originally in his book "Biophilia" - popularised the Biophilia Hypothesis ${ }^{\mathrm{iv}}$; which suggested that we as human beings tend to stay surrounded by aspects of nature. In other words, Biophillia is the connection we as human beings seek with other living organisms.

Recently; seeking for healthy and hence productive built environment through good relation with the natural world; many studies incorporating Biophilia with architecture had been conducted. Many classifications had proposed to the attributes of the architectural space that support the concept of Biophilia. First laid out by Cramer and Browning in Biophilic Design (2008), a preliminary list of what is called "biophilic conditions". ${ }^{v}$ It is based on man- nature relationship. They classified the Biophilic conditions into three categories: direct experience of nature, indirect experience of 
nature and experience of space and place. Direct experience of nature represents the actual contact with environmental features in the built environment in the form of light, air, water, plants...etc. Indirect experience of nature represents imitating images of nature; such as using natural materials or colours, natural forms or simulating natural light and air. Finally; experience of space and place which is the spatial features characteristic of the natural environment that have advanced human health and wellbeing for instance; organized complexity and mobility and way-finding.

Another approach to the study of biophilia is done by Ryan and her colleagues. William, Ryan and Clancy agreed that Biophilic design can reduce stress, enhance creativity and clarity of thought, improve our well-being and speed up healing. They established three categories meant to help define biophilic buildings; that are Nature in the Space, Natural Analogues and Nature of the Space ${ }^{\text {vivii }}$.

They suggested 14 patterns to apply biophilia in interior spaces ${ }^{\text {viii }}$. Some of these patterns are related to the man-nature connection and the other patterns associated with the design of the space and its elements. The 14 patterns were classified into the three main categories that mentioned above.

These two approaches to study Biophilia in the built environment will be the base of the model to incorporate the principles of biophilia into the architectural design of workplaces in order to propose a "Biophilic Design Criteria for Productivity (BDCP)". With a closer look to the above two approaches to the study of biophilia in the built environment; it is not clear the role of the architectural design in achieving the biophilic space that supports the convenience and production of users. These two approaches also lack the differentiation between new buildings under design and existing buildings that need to be retrofitted to enhance occupants' well being. Also, neither of the two previous models or any another model provides an order of priorities in the case of conflicting models or patterns of biophilic design in a way that does not allow all of them to be achieved.

\section{ANALYZING EXAMPLES OF BIOPHILIC WORKPLACES:}

It is difficult to measure productivity; so the study will focus on the built-environment features that lead to calmness, comfort and happiness of the employees. The Analytical 
study was held to identify and quantify associations and test hypotheses; identify causes of comfort, happiness and calmness for employees and determine whether an association exists between categories and subcategories. The study analyzes five

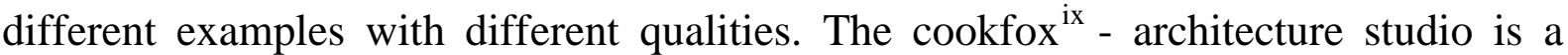
floor in an old building that is renovated. Glumac ${ }^{\mathrm{x}}$ Shanghai office is a historical building first designed by Louis Sullivan. David and Lucile Packard Foundation ${ }^{\mathrm{xi}}$ is a new three stories building. Kickstarter ${ }^{x i i}$, commercial headquarters is a historic renovated building. Finally, Google office building, Chicago, USA could be considered as new building since it was a seven stories windowless structure before it is redesigned as office building. The first two examples are LEED certified and Google office building obtains three green certificates that are LEED v4, the WELL Building Standard, and the Living Building Challenge's Petal Certification ${ }^{\text {xiii }}$.

The analysis will follow the model of William, Ryan and Clancy with its 14 patterns because it is more detailed and comprehensive than any other model.

Tables from 1 to 5 will show analysis of the five examples and will deduce the main design attributes related to each category of biophilic elements. 
Table 1: Example1: COOKFOX - ARCHITECTURE STUDIO, New York, USA, 2016

\begin{tabular}{|c|c|c|c|}
\hline $\begin{array}{|lll|}\text { overview } & & \\
\text { Design } \quad \text { Team: } & \text { CookFox } \\
\text { Architects LLP } & \\
\text { Awards: LEED } & \text { Platinum, } \\
\text { Commercial } & \\
\end{array}$ & \multicolumn{2}{|c|}{ Biophilic elements } & Architectural manifestation \\
\hline $\begin{array}{lll}\text { Design Team: } & \text { CookFox } \\
\text { Architects LLP } & \\
\text { Awards: LEED } & \text { Platinum, } \\
\text { Commercial } & \end{array}$ & 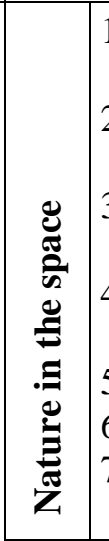 & $\begin{array}{l}\text { 1. Visual Connection with } \\
\text { Nature: } \\
\text { 2. Non-Visual Connection With } \\
\text { Nature: } \\
\text { 3. Non-Rhythmic } \\
\text { Stimuli: } \\
\text { 4. Access to Thermal \& Airflow } \\
\text { Variability: } \\
\text { 5. Presence of water } \\
\text { 6. Dynamic \& Diffuse Light } \\
\text { 7. Connection with Natural } \\
\text { Systems: }\end{array}$ & 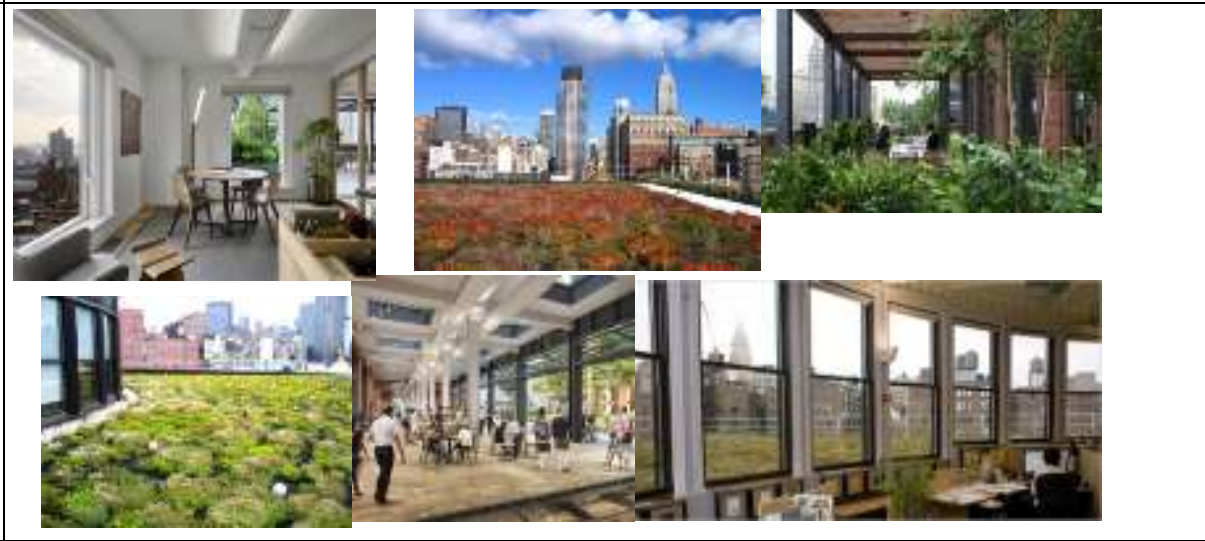 \\
\hline 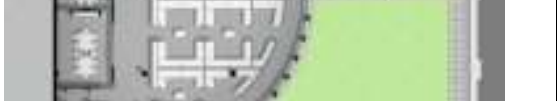 & desigr & $\begin{array}{l}\text { Elevated garde } \\
\text { the office }- \text { sou }\end{array}$ & $\begin{array}{l}\text { den) - Large operable windows - light well - plants throughout } \\
\text { ells from the roof - skylight }\end{array}$ \\
\hline 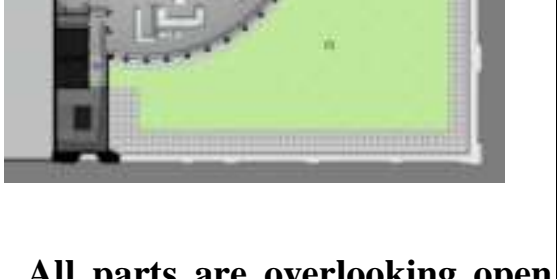 & 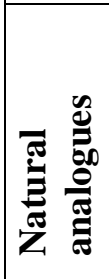 & $\begin{array}{l}\text { 8. Biomorphic Forms \& } \\
\text { Patterns: } \\
\text { 9. Material Connection with } \\
\text { Nature: } \\
\text { 10.Complexity \& Order: }\end{array}$ & 78 \\
\hline \multirow{3}{*}{$\begin{array}{l}\text { All parts are overlooking open } \\
\text { spaces through roof and light } \\
\text { well }\end{array}$} & \multicolumn{3}{|c|}{ design details } \\
\hline & 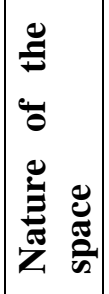 & $\begin{array}{l}\text { 11. Prospect: } \\
\text { 12. Refuge: } \\
\text { 13. Mystery } \\
\text { 14. Risk/Peril }\end{array}$ & 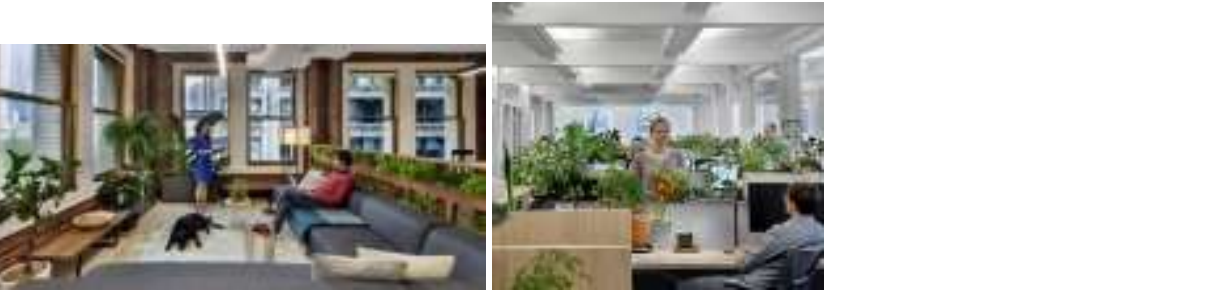 \\
\hline & \multicolumn{2}{|c|}{ design details } & ffice partitions, and conference rooms enclosed on three sides \\
\hline $\begin{array}{l}\text { Most relevant Biophilic design } \\
\text { elements }\end{array}$ & \multicolumn{3}{|c|}{ Visual and non visual Connection with Nature - Natural Materials - refuge } \\
\hline
\end{tabular}


Table 2: Example2: Glumac shanghai office, Shanghai, China

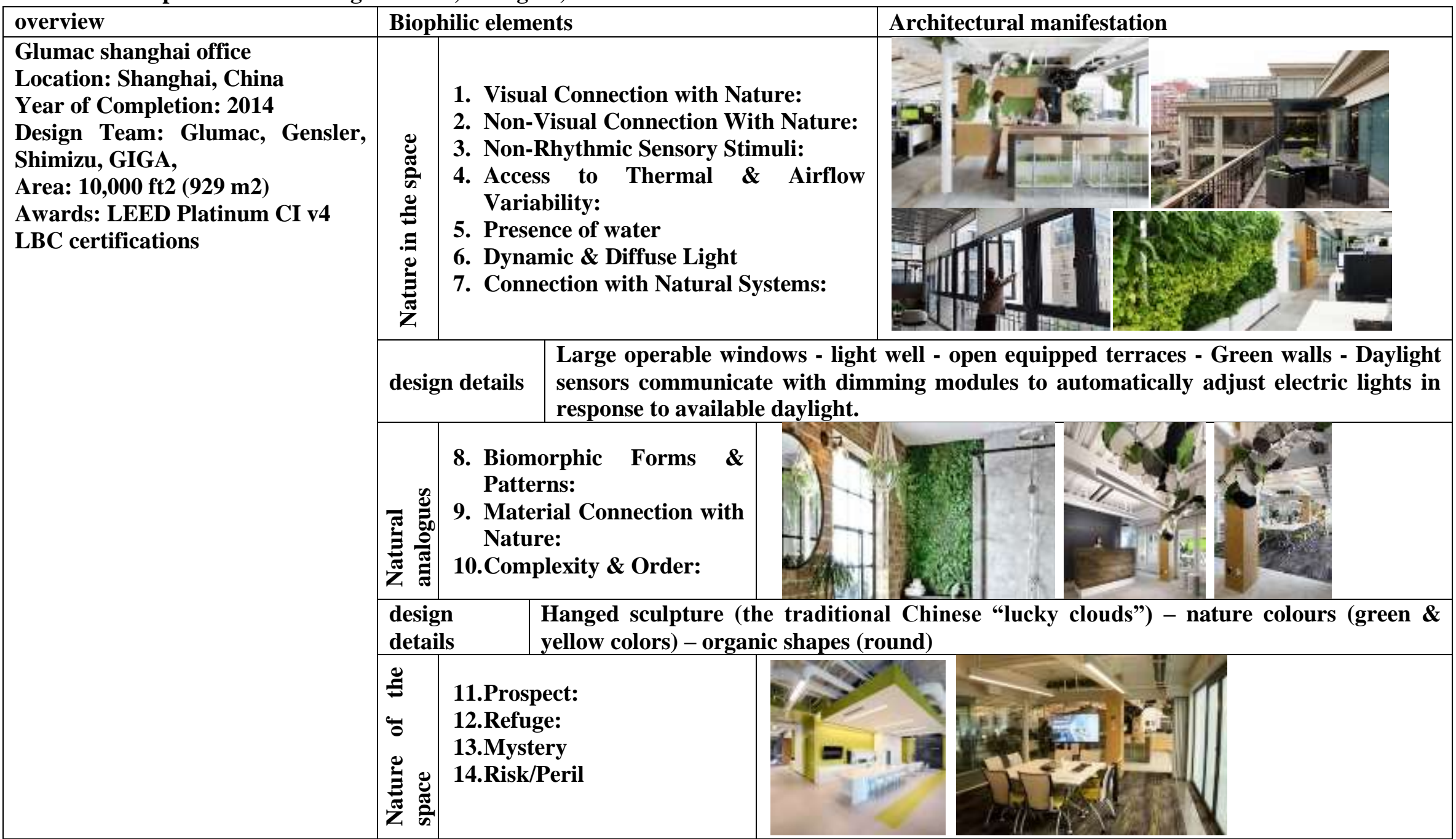




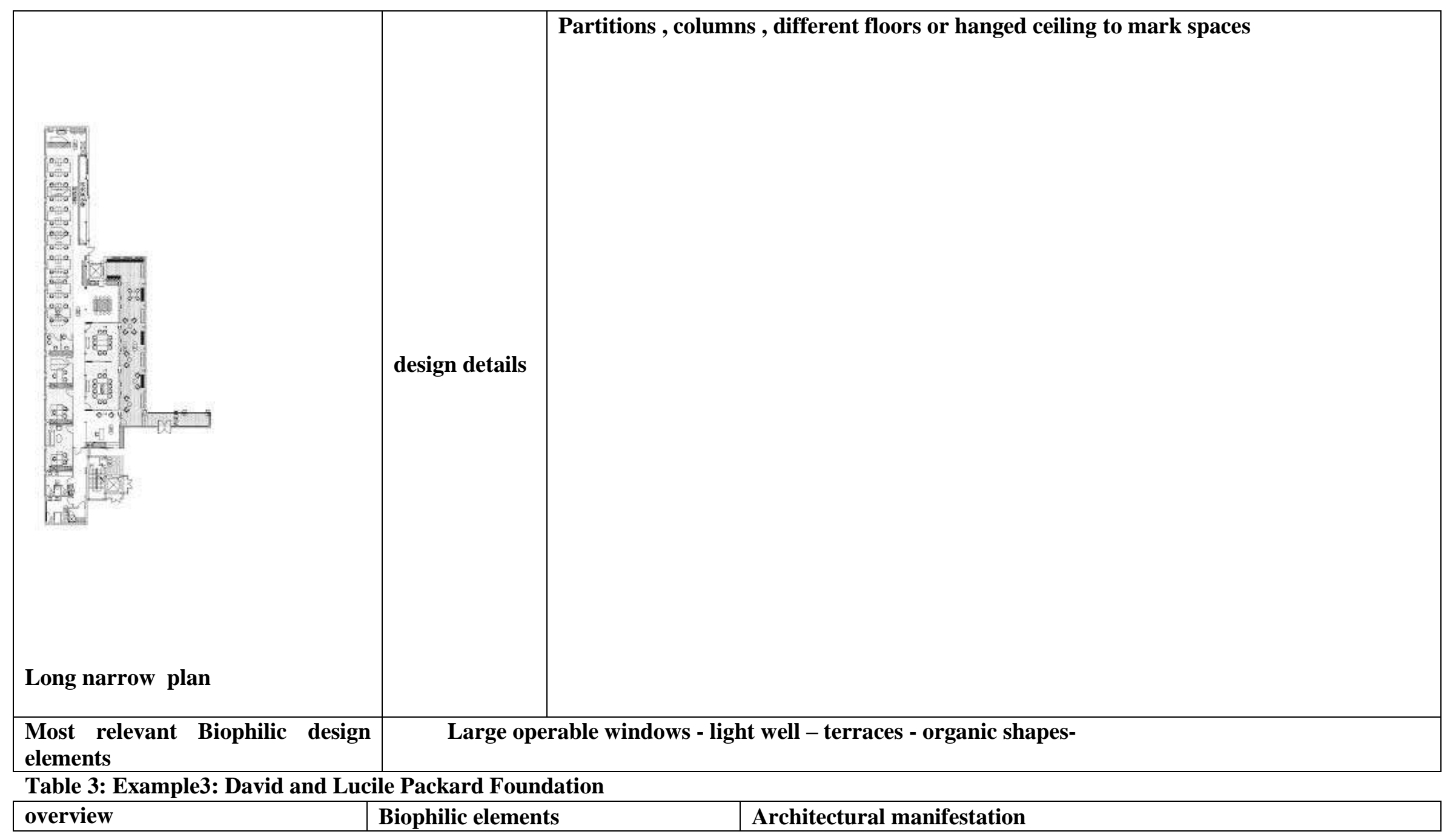




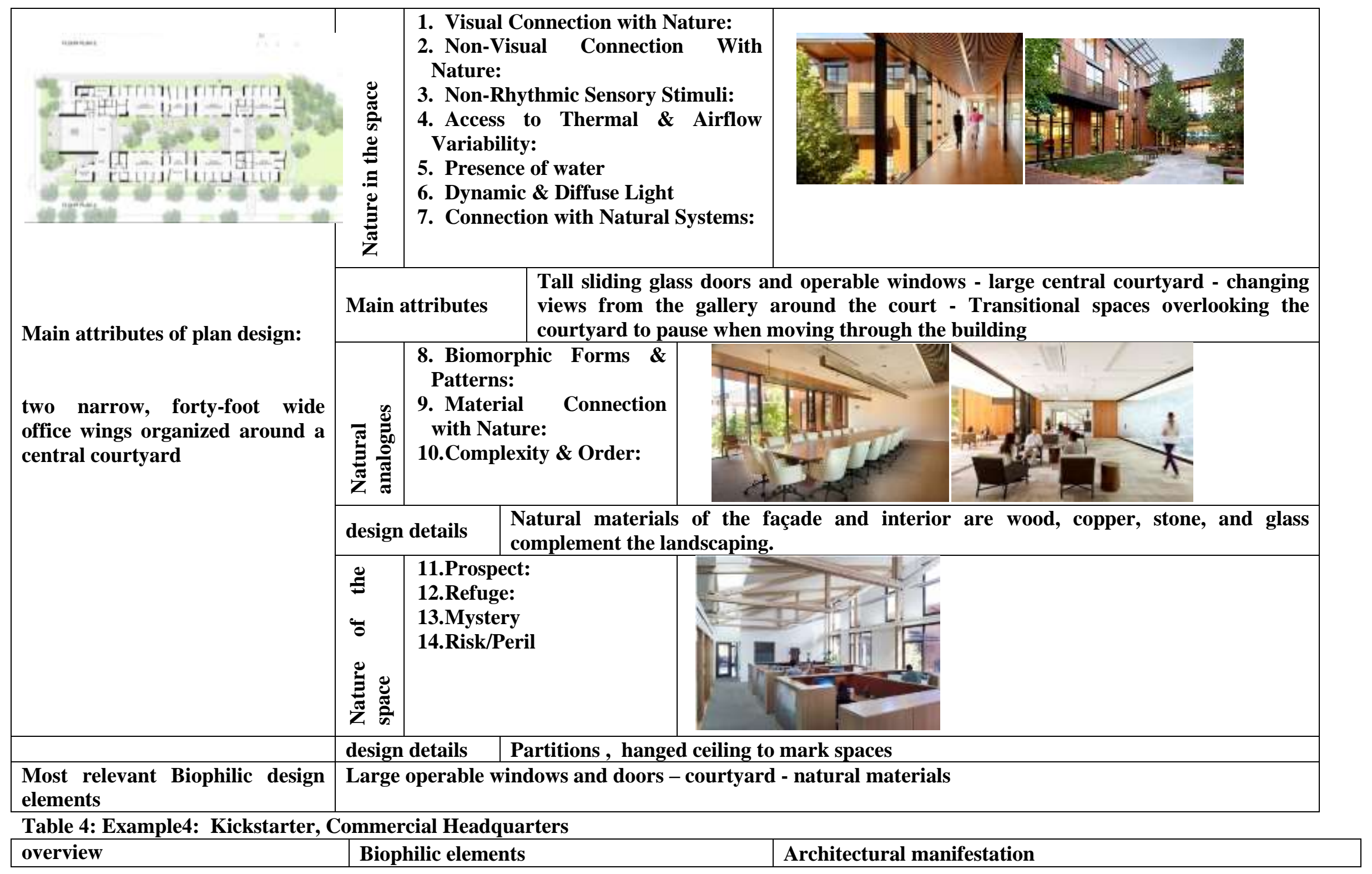




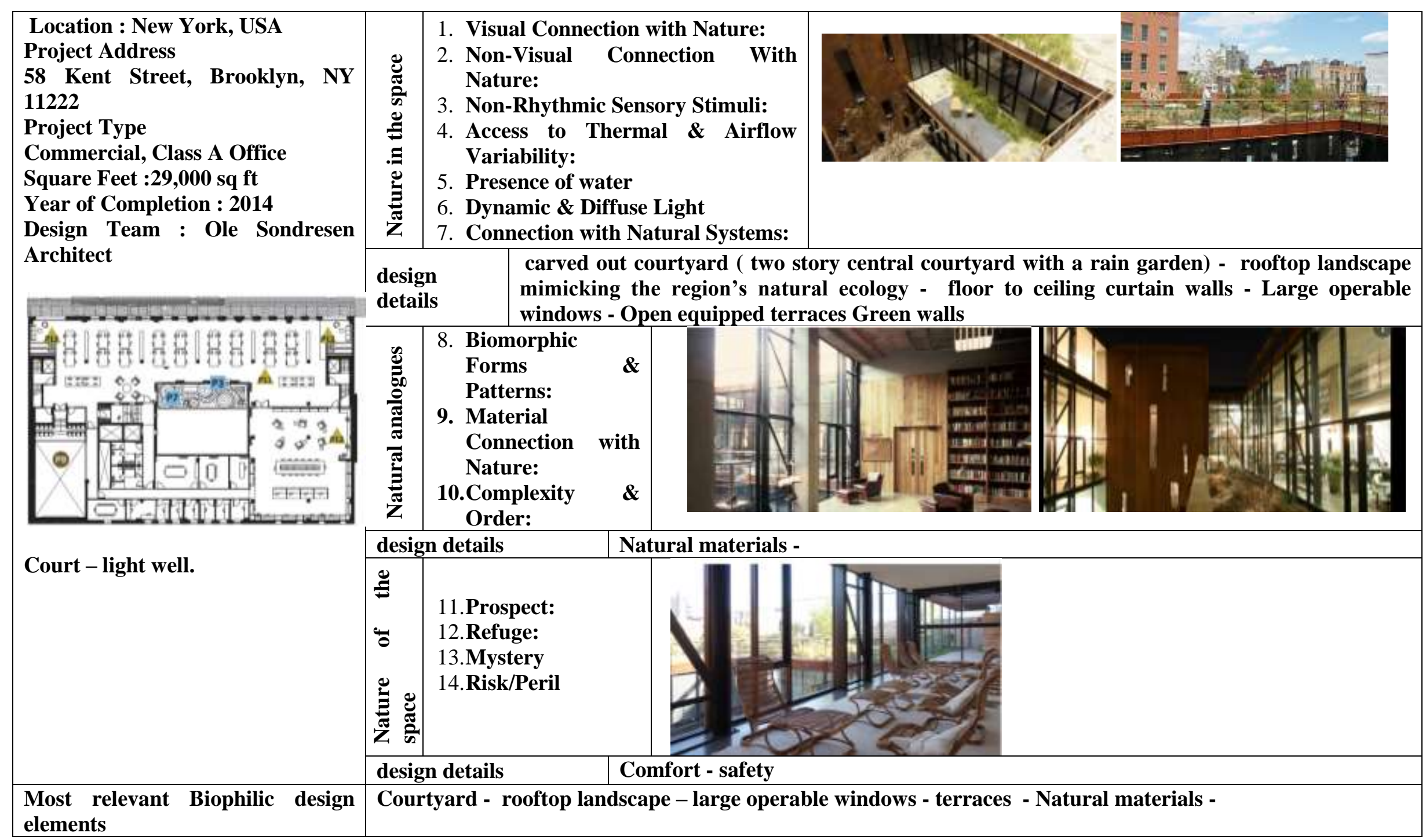

Table 5: Example 5: Google, Chicago, USA

\begin{tabular}{|l|l|}
\hline Overview & Biophilic elements \\
\hline
\end{tabular}




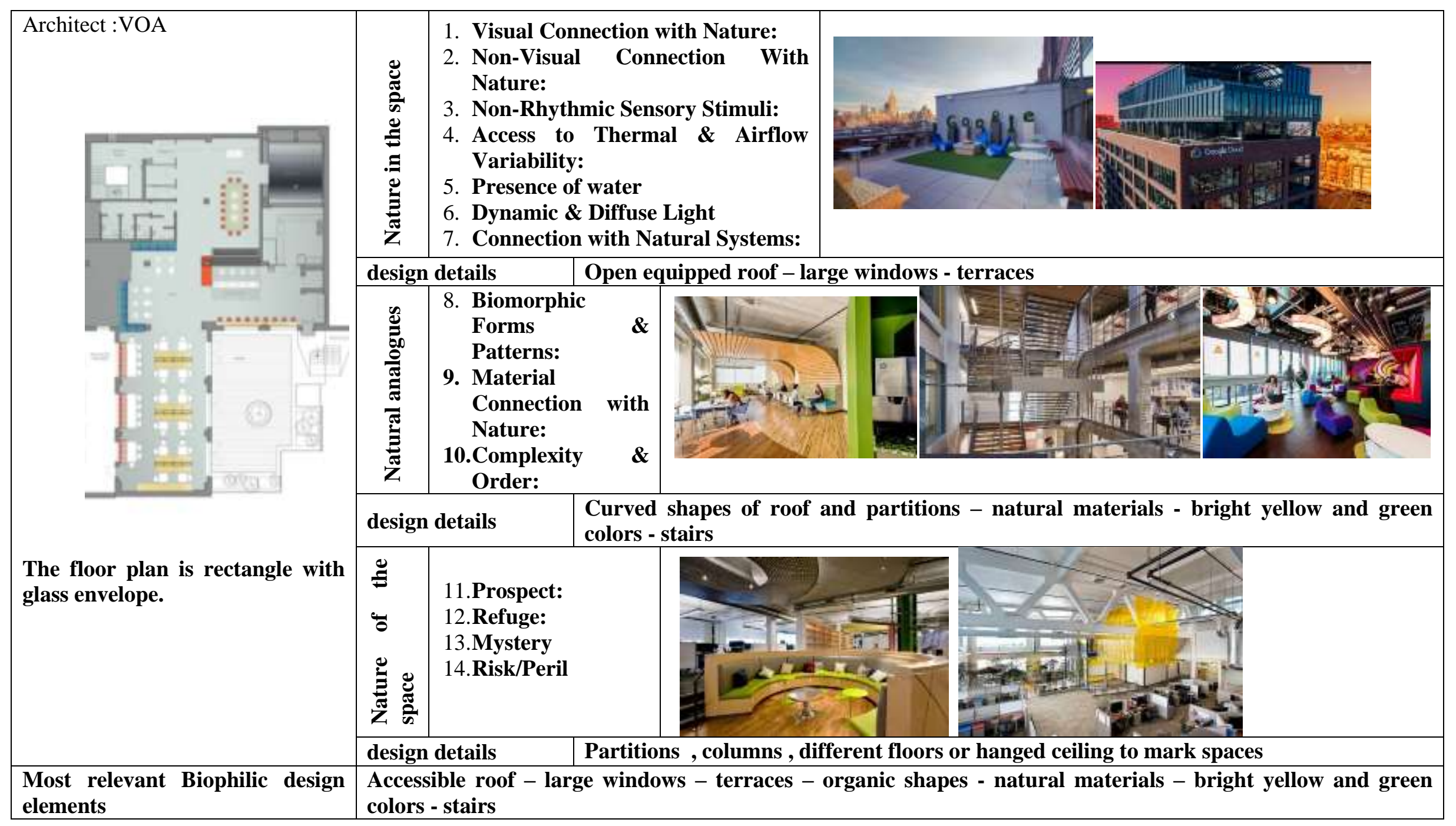


After analyzing the previous biophilic workplaces examples, we can conclude that the most frequent biophilic design element is the direct connection with external nature. Direct connection with nature includes visual and non-visual connection, natural daylight and ventilation which were achieved through vegetated accessible roofs, patios, large operable windows, terraces and light wells.

The second most frequently used biophilic design element is using natural materials, colours and forms inside the spaces.

\section{Assessing and rating the biophilic design elements:}

Based on the finding of the previous analysis study; a survey of a random sample of employees towards the frequent used biophilic design elements was designed. The aim was to assess biophilic design elements' effect on their satisfaction with their workplace and to rate the importance of these design elements. The survey questions are attached in appendix 1.

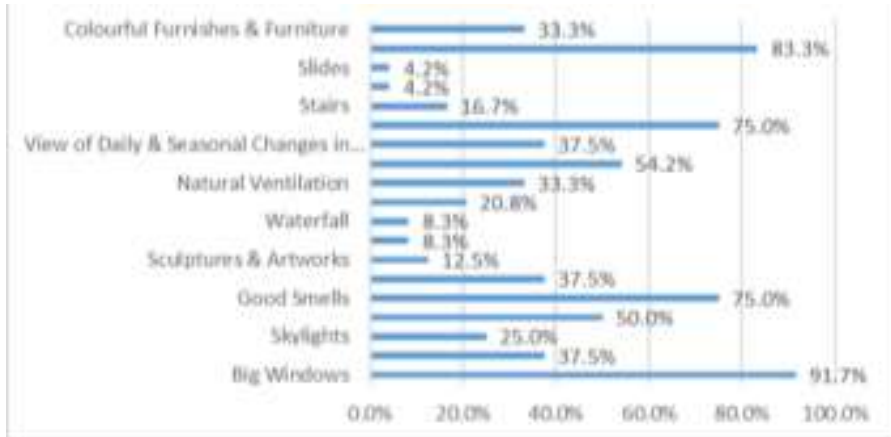

Diagram 1: Click on the features below that you prefer to find in your workplace

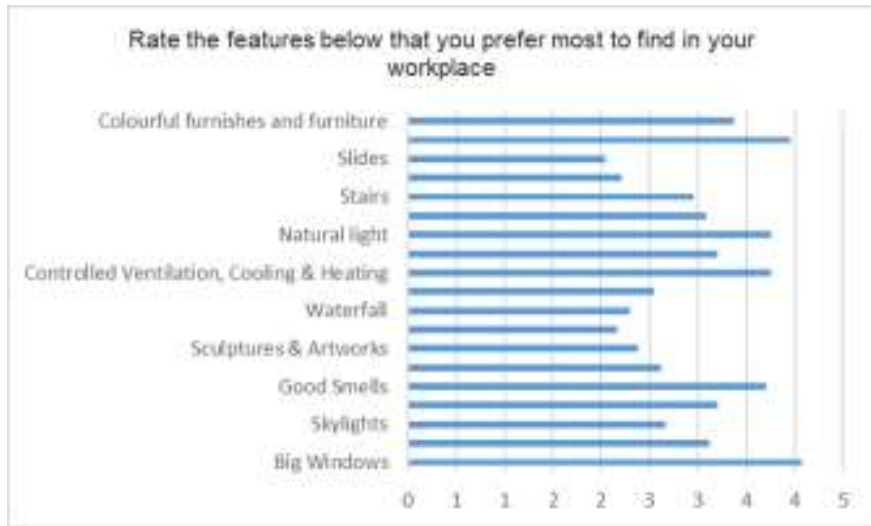

Diagram 3: Rate the features below that you prefer most to find in your workplace

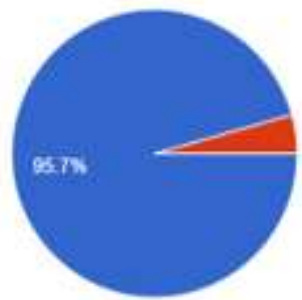

Diagram 2: which is more important to find in your workplace?

Big window overlooking a garden Plants inside the workplace 0

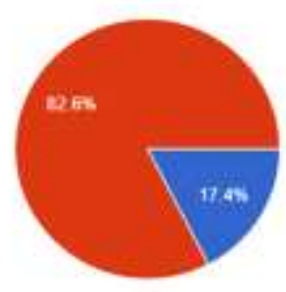

Diagram 4: which is more important to find in your workplace?

Good natural ventilationo

Controlled ventilation, cooling \& heating 
Diagrams 1, 2, $3 \& 4$ wrap up the significant responses to the survey. From diagram 1 the response of the question asking to click on the features below that you prefer to find in your workplace; we found that big windows is the most preferable design element then comes comfortable furniture in the second place. Surprisingly good smells comes before natural light. Biomorphic forms and elements (stairs, ramps, arches) have limited effect on users' satisfaction. Water features have limited effect too. Users' prefer colorful furniture and finishes themed with blue as shown in diagram 2.

They prefer to overlook a garden than having plants in pots inside their workplaces with an overwhelming consensus. Likewise, they prefer controlled ventilation, cooling and heating more than good natural ventilation.

From the survey we found that big windows overlooking garden with controlled ventilation, cooling and heating is the perfect workplace features from the users view.

\section{BIOPHILIC DESIGN CRITERIA FOR PRODUCTIVITY (BDCP)}

To incorporate the biophilic design elements in architecture design; it needs a plan to be applied in new and existing workplaces. This paper proposes a Biophilic Design Criteria for Productivity (BDCP) in the built environment through enhancing Occupants' connection with nature and thus offers productive workplaces.

First of all; we have to determine whether it is a new building or an existing building that needs to be retrofit to achieve biophilic benefits on occupants. For an existing building; adding a patio or a light well could be impossible. Also changing the floor plan shape is very hard to be done.

On the other hand; when it comes to interior design elements, the difference between new and existing building is not that great. In other words; for a new office building; designers must mind mass morphology, building envelope and infill elements, while in an existing building only building envelope and infill elements are the components of the design criteria. 
Choosing the site of an office building beside a good view enhance the biophilic quality of the office building and constitute the first step in applying a Biophilic Design Criteria for Productivity (BDCP) in workplaces.

Mass morphology: the width of floor plan must be narrow in order that natural daylight penetrates deep. Also, narrow plans give the opportunity to all occupants to be in contact with outer environment. Building mass has to include patios, courtyards and terraces.

Building envelope: it has to contain large clear openings overlooking the good view and stacking workplaces near the view.

Infill elements or interior elements: natural comfort furniture with spaces blue color themed.

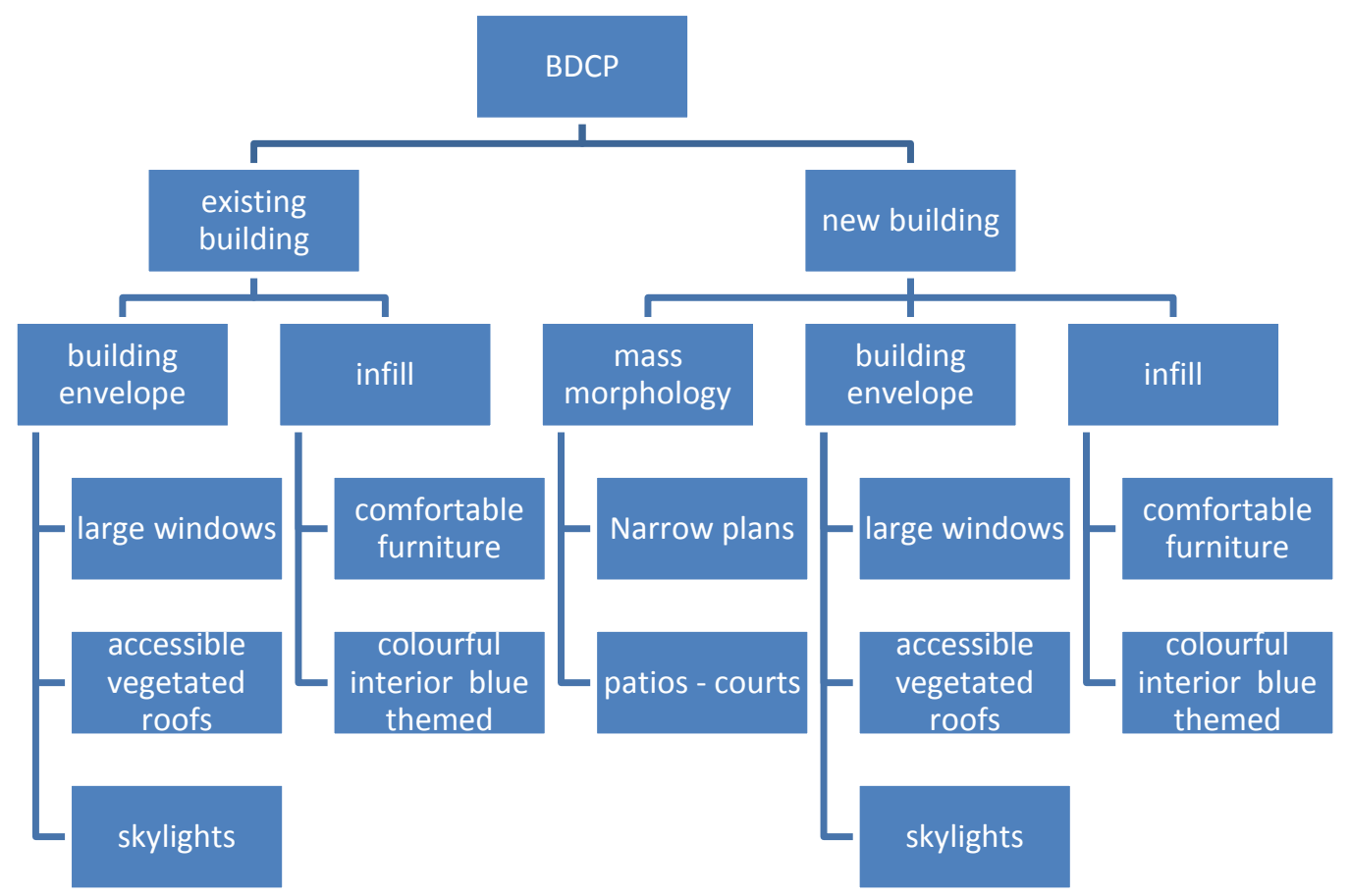

Figure 1: Biophilic Design Criteria for Productivity (BDCP) in workplaces

\section{Conclusion}

1. Biophilia supports both physical and social components of the workplaces.

2. Adopting a Biophilic Design Criteria for workplaces is a must. It has many positive effects on the employees. 
3. Choosing the site of an office building beside a good view enhance the biophilic quality of the office building and constitute the first step in applying a Biophilic Design Criteria for Productivity (BDCP) in workplaces.

4. The most evident realization of the principle of biophilia, without a doubt, is the contact with the surrounding nature, which requires open facades, a good view, and a height of the building that opens the field of view so that it is not obstructed by any of the neighbouring buildings.

5. The elements of nature inside the building (plants, water), which require special care and maintenance in order to remain healthy and not become a source of inconvenience, don't influence the users 'satisfaction.

6. Detailed studies could be held to test alternatives and optimize the building wings' length, width, and height to ensure a pleasant and welcoming outdoor environment throughout the year.

7. Emphasizes spaces that blur the lines between indoors and outdoors.

8. Choosing the best biophilic design must be accompanied by a simulation environmental study in order to evaluate the effect of the favourable elements chosen by the employees asked in the survey (Big windows, outdoor garden) and how it affects the environment indoors \& outdoors. 


\section{Appendex 1}

Google form questionnaire

This questionnaire is for scientific purpose. It is designed to discover elements in the interior design of workplaces that makes you more comfortable and work efficiently.

1. Click on the features below that you prefer to find in your workplace

○ Big windows

- Patios

- Skylights

○ Calming Sounds

- Good smells

- Indoor plants

- Sculptures and artworks

- Fountain

- Water fall

- Water Pools

- Natural ventilation

○ Autonomous control HVAC

- View of daily and seasonal changes in nature

- Natural light

- Stairs

- Arches

- Slides

- Comfortable furniture

- Colourful furnishes and furniture

2. Which colour theme do you prefer to have in your workplace?
- Blue
- Yellow
- Green
- Red
- Brown
- Grey
- Black

3. Do you accept presence of some small size animals or birds (birds- parrot - cat - dog) near you in your workplace?

○ Yes

○ No

4. Which is more important for you to find in the workplace?

$\circ$ Big window overlooking garden

- Plants inside the space

5. Which is more important for you to find in the workplace?

- Good natural ventilation

- Autonomous control HVAC

6. Rate the features below that you prefer most to find in your workplace

$\circ$ Big windows

○ Patios

- Skylights

- Calming Sounds

- Good smells

- Indoor plants

- Sculptures and artworks

- Fountain

- Water fall

- Water Pools

- Good natural ventilation

- Autonomous control HVAC

- View of daily and seasonal changes in nature

- Natural light

- Natural ventilation

- Stairs

- Arches 
- Slides

- Comfortable furniture

$\circ$ Colourful furnishes and furniture

Thank you

\section{References:}

i Richard Louv, The Nature Principle (Reconnecting with Life in a Virtual Age, Algonquin Books, 2012.

ii Anthea Court, The effects of exposure to natural light in the workplace on the health and productivity of office workers: a systematic review protocol, The University of Adelaide, Australia, 2010

iii Kellert, S. and Calabrese, E. 2015. The Practice of Biophilic Design.

www.biophilic-design.com

iv Edward Osborne Wilson, "Biophilia”, Harvard University Press, UK,1984

v Cramer and Browning , Biophilic Design (2008),USA,2014.

vi William Browning, Hon. Catherine Ryan and Joseph Clancy; "14 patterns of biophilic design improving health and well-being in the built environment", Terrapin,

${ }^{\text {vii }}$ Sara Mohamed AbdelMeguid), Biophilic Design (Strategies for hospitals retrofit), master thesis, Ain Shams University, Cairo 2014

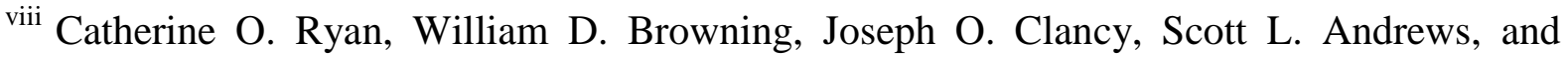
Namita B. Kallianpurkar, "Biophilic Design Patterns Emerging Nature-Based Parameters for Health and Well-Being in the Built Environment", Terrapin Bright Green LLC United States, 2014

${ }^{\text {ix }}$ https://www.terrapinbrightgreen.com/wp-content/uploads/2015/11/641-Case-Study-

Fall15.pdf

${ }^{\mathrm{x}}$ https://www.lutron.com/en-

US/CaseStudyPDF/3684143_Glumac_Shanghai_Case_Study_sg.pdf

${ }^{x i}$ https://living-future.org/biophilic/case-studies/david-and-lucile-packard-foundation/

xii https://www.terrapinbrightgreen.com/wp-content/uploads/2015/11/Kickstarter-Spring-

16F.pdf

xiii https://gbdmagazine.com/chicago-google-office/ 